\title{
Re-Imagining Business Agency through Multi-Agent Cross-Sector Coalitions: Integrating CSR Frameworks
}

\author{
Philipp Dorstewitz ${ }^{1}$ (1) $\cdot$ David Lal $^{1}$
}

Received: 8 February 2021 / Accepted: 1 July 2021 / Published online: 17 November 2021

(C) The Author(s), under exclusive licence to Springer Nature Switzerland AG 2021

\begin{abstract}
This theoretical paper takes an agency-theoretic approach to questions of corporate social responsibility (CSR). A comparison of various extant frameworks focusses on how CSR agency emerges in complex multi-agent and multi-sector stakeholder networks. The discussion considers the respective capabilities and relevance of these frameworks culminating in an integrative CSR practice model. A short literature review of the evolution of CSR since the 1950's provides the backdrop for understanding multi-agent cross-sectoral stakeholder coalitions as a strategic determinant of today's organizational behavior. The paper turns to Werhane's coupling of moral imagination and systems thinking and forging stakeholder coalitions in problem contexts that were traditionally deemed intractable by for-profit organizations. However, it identifies the problem that the systems approach treats macro-agents (organizations, stakeholders) as given ("blackboxed") and shies away from more radically re-imagining the possibilities of reassembling agency from the bottom up. Actor Network Theory (ANT) provides such a method, which strictly commits to treating organizational behavior as a product of technological, human and environmental micro-processes. ANT, however, is lacking a genuine moral deliberative stance in designing complex CSR coalitions. In an attempt to capitalize on the respective strengths of these frameworks (Systems thinking and ANT) the paper tends to a recent iterative series of "situational transactive" models that are rooted in the US pragmatist tradition and seek to capture intelligent planning processes in complex problematic contexts. The contribution proposes a new CSR practice model, which assigns specific roles to the theoretical contributions of ANT, system thinking and pragmatism in complex deliberation processes. This model can be industry-tested in a future study.
\end{abstract}

Keywords CSR · Multi sector coalitions · Agency theory · Systems thinking · Moral imagination · ANT $\cdot$ Pragmatism

Philipp Dorstewitz

philipp.dorstewitz@aurak.ac.ae

Extended author information available on the last page of the article 


\section{Introduction}

A responsible actor, in common parlance, is a person in full possession of their cognitive, rational and deliberative capacities (e.g. as in "legally responsible") (cf. Fischer 1999). CSRdebates have the pernicious tendency to assume a juxtaposition between "responsible" business practices and "rational" economic behavior (Visser 2014; Sandberg 2008; Waddock 2004; Freeman 2004). Consequently, much theorizing is needed to mend the apparent schism between economic motives and imperatives of social and environmental responsibility (Jensen and Sandstrom 2013). Often this can be only partly achieved by demonstrating how CSR strategies may yield sustainable profits, in some cases - and under restricted conditions. It may be worth trying another starting point that avoids separating so-called business imperatives from wider sets of responsibilities of an economic agent in the first place. Perhaps it may even be possible to begin theorizing at a logical point prior to the formation of those economic agents that, with their well-defined boundaries, missions, performance measures and bottom lines - often prejudge the question of reconciling rationality with responsible action. If such a position can be obtained, deliberative activity could be focused on developing intelligent, innovative and responsible forms of agency as part of the very formation of economic actors ("agency" is defined here as, any form of coordinated activity which takes a position of concern toward the future). The present article is not addressing any particular CSR strategies or ways of motivating and reorganizing corporations toward complying with specific schedules of social or environmental responsibilities. Neither does it focus on the notion of "responsibility" and its normative or practical implications for corporate agency. At stake here are the agency theoretic assumptions and foundations for reframing CSR engagements of agency systems such as corporations and multi-actor coalitions.

This sounds highly speculative and perhaps not very realistic, because pre-existing economic agents (shareholder assemblies, executives, directors, companies, suppliers, customers, etc.) seem to belong to an order of ubiquitous and relatively stable social facts. But this may be only apparently so, as enterprises and decision-makers are continuously suspended in interactions with other organizations, individuals and an environment, and such processes transform agents and systems of agency alike (e.g., opening of the PR China under strict legal requirements have led to formation of countless joint ventures in the 1990's, many of which have now found their own identity as corporations). The following investigation will discuss the possibility of developing a flexible and transactive perspective on the formation of business agency in order to develop a model that allows integrating a systems perspective on deliberative, evaluative and imaginative processes with valuable insights gained form actor network theory (ANT). We claim that an adequate agency-theoretic model of the formation of transformative CSR agency systems needs to be transactive and imaginative at the same time. "Transactive" shall be defined in a Deweyan vein as a perspective that sees agency as emerging from active coordination processes that are embedded within and determined by an environment, instead of being the product of internal motivations of pre-existing agents. ANT opens a window on such material, technological and human conditions within which transactive agency systems (assemblages) are formed. An imaginative systems-perspective, such as espoused by Werhane $(2008,2018)$, invites taking a deliberative stance on the formation of complex coalitions. But is it enough to obtain the perspective of an "impartial spectator" (Werhane 2018) in order gain the freedom to imagine and review mental models representing agency systems, or is a bottom up, constructive stance needed that allows reopening the possibilities for reassembling agency processes, as ANT proponents envisage? If 
we choose the latter, how can we maintain a position of genuine normative guidance toward social responsibility? In search for a bridge between an imaginative, evaluative systems point of view which appreciates the complex dynamics of stakeholder models, and an agency theoretical approach that is thorough enough to envisage radical new assemblages of actants, we turn to Deweyan pragmatist notions of situational transactive agency formation and imaginative normative inquiry.

We premise our theory of deliberation on the formation of complex agency systems from material, technological and human conditions, and, at the same time invite an imaginative deliberative stance on the creation of systems, which are ready to find innovative organizational and strategic solutions to CSR problems and impasses.

\section{CSR Historical Transitions Leading up to the Present Debate}

The evolving nature of CSR and its impact on organizational behavior has gone through a series of transformative foci over the past eight years. References dating back to the late 1930's, showed a tendency from executives and the business world, to consider the term social responsibility (cf. Barnard 1938; Clark 1939; and Kreps and Murphy 1940) and it was around this period when the focus shifted towards corporate social responsibility. Indeed, in examining CSR through the 1940's and into the 1950's - we note that the focus of attention from industry practitioners and academics primarily lay within a context of analyzing the responsibilities that businesses had to society. Reflections on this particular period saw consideration being associated with the nature of the "good deeds" of business to their respective societies (cf. Bowen 1953; Eels 1956; Heald 1957; Davis 1960; McGuire 1963).

This approach swiftly moved forward, where in the 1960's, CSR was characterized by distinct social changes within the external environment leading to a shifting of societal behavior - driven by specific people, key events and by an open-mindedness of ideas (cf. Samuelson 1971; Steiner 1971; Davis 1973; Sethi 1975; Keim 1978; Murphy 1978).

At the center of many of the evolving changes with CSR during the 1970's and 1980's, was a drive towards a stronger business perspective on CSR, with a groundbreaking focus on community relations and the emergence of a social contract between business and society (Committee for Economic Development 1971). CSR was primarily characterized by an extension of philanthropy, with businesses' attention being driven towards good causes (cf. Eberstadt 1973; Eilbert and Parket 1973; Frederick 1978; Aupperle et al. 1985). Interestingly, Johnson (1971) alluded to a precursor to stakeholder theory - in relation to CSR - with an emphasis on including the interests of groups from all sectors of society. Jones (1980) observed corporate social responsibility through a lens centered around business having an obligation to constituent societal groups, other than stockholders, and beyond that prescribed by laws and union contracts. He associated the responsibilities of business with a distinct need for corporations to integrate and become more responsive to societal stakeholders. In progressing, Freeman (1984) introduced stakeholder theory to the CSR debate by linking it to strategic management, and Epstein (1987) debated business ethics with CSR in relation to corporate social policy.

During the late 1980's and throughout the 1990's, in terms of CSR, philanthropy continued, and markets continued to expand under the banner of the globalization of companies, and in addition there was the added expansion of corporations through strategic diversification. On this note, the agenda for CSR was evolving as an integration of stakeholder theory, social 
responsibility, business ethics, and their association with organizational performance (cf. Epstein 1987; Carroll 1991, 1994; Carroll 1999; Harrison and Freeman 1999; Muirhead 1999).

The twenty-first century saw a continuation of the integration of the theoretical frameworks of CSR, but with a slowing-down of the introduction of new terms, frameworks and concepts. However, this gave way to a greater emphasis on CSR with the functional areas of business, and in particular, a plethora of empirical studies including cases from across industries (cf. Griffin 2000; Husted 2000; Jones and Murrell 2001; Schwartz and Carroll 2003; Kotler and Lee 2005; Dorstewitz and Kuruvilla 2007; Sassen 2014; Waelbers and Dorstewitz 2014; Kuruvilla et al. 2018). Against this backdrop, the complexity of CSR is clearly evident, and this theoretical paper moves the debate forward in order to create an innovative theoretical model of CSR for modern-day organizations in order to advance and conceptualize debate. The conceptual model will be used as a testing instrument in future studies on innovative practices in industry specific cases.

\section{Re-Imagining Systems of Agency}

Scholars have developed systems thinking for two overlapping but distinct purposes: one is to describe the structural and functional properties of complexity in theoretical concepts (Wiener 2013 [1961], Parsons 1977), the other is to understand the transformative and adaptive nature of complexity as an approach that lends itself to designing and learning within complex systems (Checkland 1981; Churchman 1971; Ulrich 1983). The latter approach, which is more associated with soft OR and critical system thinking is less descriptive and focuses on forming and reforming mental models that facilitate understanding and orientation within complex and dynamic organizational environments. Systems thinking, in the present contribution, is more aligned with the latter approach, as it seeks to address complexity in reframing situations that contain emergent forms of coordinated agency which result from forming coalitions, re-framing boundaries, re-appraising normative guides (like interests or mission statements) and assembling natural, technological, human and other actants in a situation. Complexity here deals less with cybernetic, autopoietic or adaptive systems properties and more with imaginative modelling and normative appraisal of situations.

In several contributions (Werhane et al. 2011; Werhane 1999, 2008, 2018) explains how mental models operate in organizations by shaping boundary conditions of business processes. She couples a notion of moral imagination with systems thinking, in order to point out how moral impasses can be addressed through remodeling the contexts under which business operations take place. Coupling moral imagination with systems thinking can lead to a better integration of business-sense with morally responsible decision-making, by opening avenues to new forms of integrative agency, such as multi-agent coalitions, and multi-sector partnerships. Hence, systems perspective may help reframing mental models that overcome rather narrow definitions of a business. Importantly, Werhane provides several examples how reframing a business's position - with respect to its stakeholder groups - opens new avenues for inclusive and development-oriented agency, that a mere focus on its operation as a profit maximizing entity would forfeit. This perspectival shift defines a business-operation as part of a larger network of agents (including NGO's, worker groups, shareholders, customers, suppliers, etc.). As one example for this imaginative shift of mental models toward seeing business operations as part of larger networks, Werhane points at the Grameen Bank of Bangladesh. This profit-driven organization coalesced with BRAC, an international non- 
profit organization, to enable a micro-credit service that not only enabled development in large parts of the country, but also proved tremendously profitable for the bank. Other examples included in Werhane's discussions follow the same pattern whereby business enterprises reframe stakeholder organizations in terms of learning to see their respective operations as part of a larger network or complex system, which enables them to form coalitions and partnerships that open new avenues for successful engagement. Consequently, Werhane seeks to move beyond a traditional stakeholder model (Fig. 1).

Here, an organization places itself at the center of relations within a periphery of stakeholder groups. However, Werhane's own embraced model considers the organization as but one element in a network of stakeholders. These stakeholders form a web, connecting on a par with each other (Fig. 2). This shows a perspective on business processes as an emergent from of agency, formed within interactive network-relations - as part of a complex whole.

Werhane's contribution is significant in that she uses one important aspect in the pragmatist conception of imagination, namely that of seeing a situation in the light of its' inherent possibilities (Alexander 1993 p.384; Dewey 1934) and applies this to a systems perspective on stakeholder relations. This approach helps in understanding CSR problems, such as compliance with ecological or social standards without the interest conflicts perspective between (pre-established) economic agents, and rather with issues to be addressed in networks of transactions. In such network categories that pertain to an "agent" (boundaries, strategies, purposes, performance measures, environment, opponents, or competitors) are considered as emergent, negotiable and malleable. Active deliberation to form multi-agent network coalitions should represent situations as mental systems models. It is evident how this view invites imaginative decision-makers to cross boundaries of their organizational mindset and forge alliances or reorganize network dynamics. It is also worth mentioning that Werhane's notion of mental models can be best understood as shared mental models that operate within an organization and not reducible to individual decision-makers' cognitions, which she elaborates in her 2018 article in this journal: "as social beings we are constantly interacting with, thus

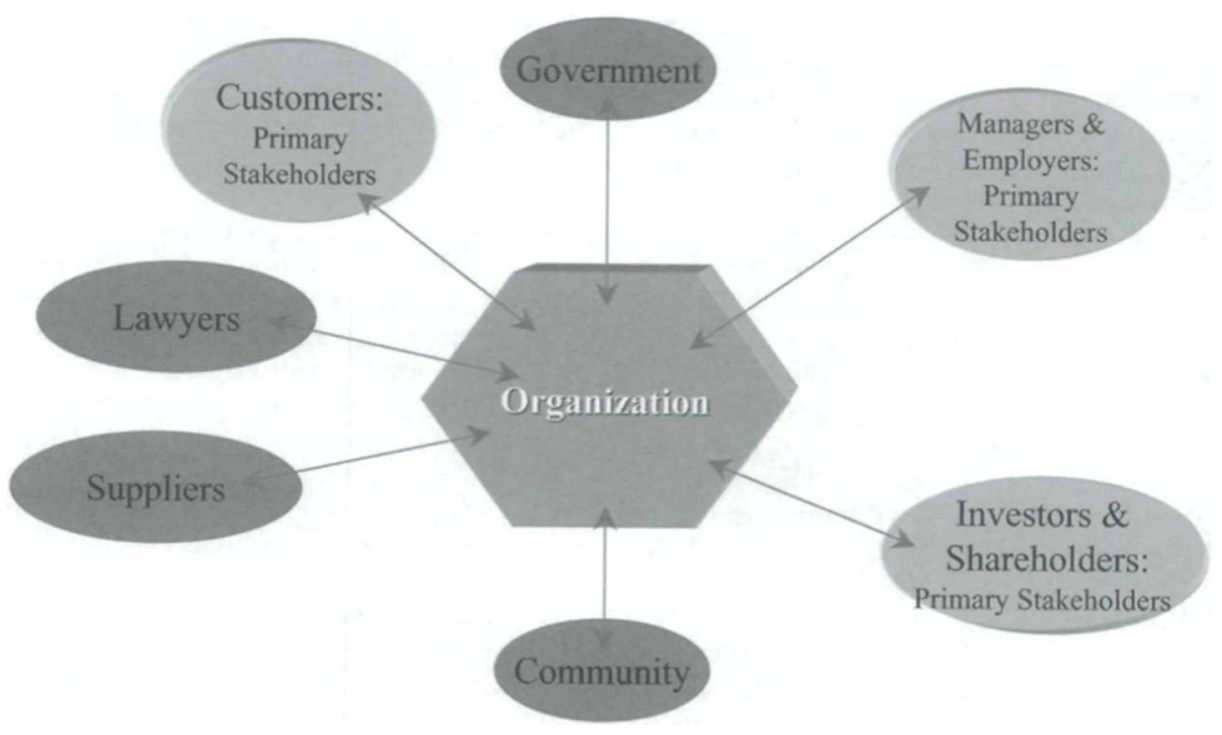

Fig. 1 Standard stakeholder model. (source: Werhane 2002, cf. Werhane 2018) 


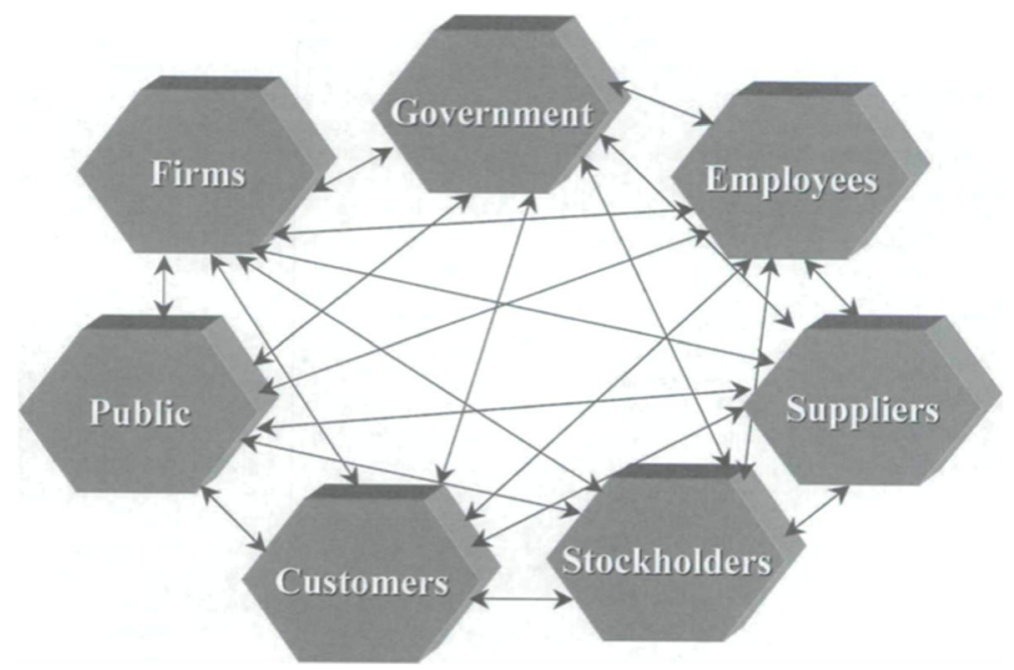

Fig. 2 Stakeholder networks. (source: Werhane 2002)

affecting and being affected by, others' mental models. These in turn are historically and culturally situated and at least partly constructed from these situational contexts" (Werhane 2018). Moreover, she insists on cultivating the imaginative ability of taking sympathetic perspectives on those individuals and groups that may be adversely affected by managerial decisions, urging decision-makers to entertain perspectives that place affected individuals in the very center of networks. This being interpreted as imaginative systems-thinking that may productively lead to more ethically defensible considerations of all stakeholders, thereby leading to an active search for opportunities to rearrange business-processes toward engagement in CSR effectively, which would be economically beneficial to deeper and more meaningful partnerships.

While a systems-view on stakeholder networks may open opportunities for new coalitions, it tends to treat components of these systems as given organized entities and agents. Organizational agency can subsequently focus on rearranging networks, e.g., by forging partnerships or coalitions with existing stakeholder groups, without the necessity of looking at the material processes underlying the formation of agency within these networks. In fact, a systems perspective often has the tendency to subsume micro-processes within holistic structural or functional models (ANT scholars call this "punctualization") thereby concealing or "blackboxing" underlying processes of agency formation. Werhane seems aware of this problem, when identifying it as the office of imagination, to shift from the abstraction of talking about organizations and their stakeholder environment to taking the perspective of particular individuals, such as women working in sweatshops, (Werhane 2008, 2018). However, her focus on mental models and impartial spectators does little to redirect the understanding of organizational agency processes. Seeing organizations as agents that interact with other organizations, leaves basic assumptions about macrophenomena intact. That should be questioned as we argue below.

Sassen $(2013,2014)$ warns that theoretical concepts in the social sciences and mental models often function as smokescreens to hide more of reality than they reveal. This is particularly evident when concepts refer to aggregated phenomena, or organized actors (such as economic growth, nation states) which often function to conceal "subterranean" facts. E.g. 
advancing land-grabs or environmental depletion can hollow out concepts of "nationalterritory" or "sovereign-state", and mass "expulsions" of people into slum-dwelling, and informal sectors of the economy may distort accounts of "GDP" or "growth" by no longer being part of any official accounting. The same may be said of aggregated systems concepts attributed to CSR actors ("organisations", "coalitions", "bottom lines", "public-private-partnerships" or "eco-balances") if they remain subject to macro-level theorizing. Werhane's systems perspective on CSR constitutes a great advance compared to traditional views on organizational agency that perceive other stakeholders or economic agents - simply as an "environment" to be identified as resources or constraints. Yet the proposed systems perspective shies from more radically re-imagining possibilities for reassembling organizational agency bottom up. This, however, requires a different theory of organizational agency, one which considers complexity more deeply.

\section{Transactions in Actor Networks (ANT)}

Actor Network Theory (ANT) is a methodological approach which considers human behavior, technological intervention and material causation on a par with each other as interlocking processes. Coordinated agency, i.e., complex coordinated behavior, is a collaborative product of all elements that are active in a situation. These active elements in a situation or "actants" can be human or non-human, natural or technological, and they cut across any division between the merely causally law-governed, and the intentional or the semiotic meaningful. Actants can be as variegated as humans ambitions, traffic signals, sea-scallops, weather conditions, financial instruments, poems or scientific publications etc. Anything that has a direct formative bearing on action must be regarded as an active ingredient ("actant") in the formation of agency. Agency is thus always a co-authored process, in which human intentionality does not necessarily play a distinguished constitutive role. Actor Nework Theory quite readily opens itself to purely technological agency such as self-regulating thermostats or AI. ANT easily goes as far as characterizing debris rolling down a hill as "negotiating" (in a literal sense) a path. ANT has been developed since the 1980's by scholars such as Callon (1981, 1986) Law (Law 1986, 1991, 2008; Law and Hassard 1999), Latour (2005, 2008) and others. This methodological program helped understanding how organizational agency processes are assembled from networks of material, human and technological elements. For ANT scholars like Law and Latour, social reality, especially at the structural level represented by Werhane's systems thinking, is never given - but always a reality in the making. ANT views reality continuously as "incomplete," "contested" and "temporary" (Law, 1992). ANT has its strength in explaining how material conditions e.g., the design of technology shapes agency and a-fortiori moral agency. Also, it offers an analytic perspective for understanding organizational agency, including sectoral and cross-sectoral coalitions as an emergent product of material and social transaction (Egels-Zandén and Wahlqvist 2007). Gond and Ligonie (2017) applied ANT to reframe how businesses interacted within their respective technological and human environments. ANT develops a counterpoise to the structural/functionalist systems approaches, by emphasizing the materiality and performativity of social structures that need to be "enacted and enacted again" (Law 2008, p.13). These include in their enactment material and technological actants, understood as active components that only in their interaction with other elements and humans form systems that deserve to be labelled as "actors" or "agency systems". Those actants, however, are not abstract institutional actors, such as "suppliers" or 
"social norms and customs" (see Fig. 2). Latour (2005, p.128) explains: "A good ANT account is a narrative or a description or a proposition where all actors do something and don't just sit there." Of course, actants can be groups or organizations, but the narratives of ANT - are those of actual transactions that form complex forms of agency. ANT therefore brings macro-social phenomena such as organizations, interests, coalitions or economic and technological conditions down to micro-analyses of component materials, technology, performances and "translations". A "translation" in ANT parlance, refers not to a linguistic transliteration but to a process of interest and power formation, as in summarizing individual efforts into a "we" (Callon 1981, 1986). Callon (1986; cf. Weaver et al. 2015) identified four progressive phases of "translation" as:

- Problematization: agreeing on the need for change, identifying areas and actors involved in change action;

- Interessement: actors agreeing on problem-definitions;

- Enrolment: actors committing to change process;

- Mobilization: detailing organizational actors to be involved, recruiting them for participation network action.

Thus, as an approach to multi-actor CSR agency, ANT can be represented by the following model:

This model constitutes an iteration of a schema proposed by Weaver et al. (2015). "Punctualization" refers in ANT lingo to a process of forming higher order agencies (such as organizations or established coalitions) that function as widely recognized reference points for strategic agency. All such references to aggregate entities, such as higher order agencies, systems, coalitions can then be addressed by using labels and concepts. ANT warns that we must not succumb to the temptations of treating these entities and the referents of such macroconcepts as reified existences. We should always treat such concepts as "black boxes", and instead of simply relying on them in our theoretical analyses, we should regularly attempt to open them by looking at the material, technological and human processes that underlie them.

\section{Systems Perspective and ANT}

A systems perspective, as suggested by Werhane, must rely much on what ANT scholars would call "black-boxes" i.e., ready-made and established entities that populate mental models of systems thinkers. ANT strives to open these black-boxes and understand how agency systems is assembled from human and non-human actants (e.g. technology). These microanalyses make phenomena tractable, when they are often hidden behind theoretical constructs (such as shareholder value, or an organization's strategy), and in an advancing technological age, they allow better than other explanatory frameworks to account for the formation and transformation of complex forms of agency and social change. Normativity enters the ANT perspective when assessing how agency systems embody norms or channel behavior, which are often inherent in material conditions of technological design, like famously exposed in Latour's (1994) analysis of traffic humps and automatic seat-belt alerts. This leads towards understanding how a micro-analysis opens avenues for addressing CSR problems and creates new opportunities for collaborations between entities (actors and actants) belonging to different stakeholder groups. 
However, as Waelbers and Dorstewitz (2014) pointed out, actor network theories are able to explain moral behavior as a product of actor network assemblages, they have weaknesses in terms of obtaining a truly normative standpoint of deliberation. Hence, it may seem that ANT is purely descriptive in its analysis of how moral injunctions are embodied in actor networks and how behavior is channeled by techno-human assemblages. Yet this would be a mistake. Such theorizing as undertaken in ANT is not innocent, as ANT reveals how (scientific) accounts of assembling agency from component actants are not comments by a neutral bystander. Reflecting on the assemblage of agency systems, assists participants in defining and "translating" opportunities for action. In this manner, ANT makes its bid to open new avenues for tackling CSR issues that were previously hidden behind guises of established theoretical constructs and mental models. This sounds akin to Werhane's (2018) “impartial spectator" but it goes beyond the idea of opening opportunities for reframing and reassembling by stepping back and bracketing established mental models, because every consequent ANT analysis understands itself as an active component in a situation. Nevertheless, ANT fails to provide a genuine evaluative stance for guiding agency and social change, particularly when its' strength is during analyzing CSR issues. Impulses that ANT style theorizing can give on the direction of future, have no normative direction, and ANT provides no resources for prioritizing one form of assemblage over another. Indeed, when observing how people rarely change their behavior, primarily from the perspective of moral arguments, and comparing this to the influence of technological solutions in channeling behavior toward moral ends, Latour arrives at a pessimistic view on moral human agency after the enlightenment model of rational practical deliberation (see: Latour 1991, 1994). Consequently, ANT tends to down-play any difference between autonomous moral human deliberation and technologically mediated or "delegated" (Latour 1991) moral behavior. "In ANT, people are presented in a behaviorist manner, robbed of their core identity as moral beings" (Waelbers and Dorstewitz 2014), and this extends in ANT to assembled forms of organizational agency.

\section{Transaction - A Pragmatist/Naturalist Legacy}

Two naturalist approaches from the nineteenth century, Darwin's and Dewey's, were the very avant-garde of an ecological agency theory, that should be acknowledge as intellectual predecessors of ANT and other contemporary theories, such as systems biology, or ecological rationality. Both consider living organisms including humans as transient and constitutively embedded within an environment that they transform and that transforms their very organization at the same time. Dewey calls this the dialectic of "doing and undergoing" (Dewey 1934). All agents and actions are suspended within environments that co-shape both actions and their authors. "Transaction" for Dewey denotes an even more radical perspective on an environment or "situation" as a whole in which agents and objects mutually shape and transform their organization, both agents and environments are only the product not the antecedents of such "transactions". The category of an "agent" is for Dewey, always a trans-active notion, only realized within and through a context.

These ideas can be linked back to organizational behavior. Organizational agency is formed and transformed in their commerce with other entities (technology, customers, legal actants, and countless initiatives of stakeholder groups). As in ANT, an organization is thus an assemblage of actants. Hence the agency of corporate decision-makers can be seen to appear as a process of transactions within complex environments. However, as Waelbers and 
Dorstewitz explain Dewey and ANT part ways as Dewey insists on the importance of obtaining a truly evaluative deliberative standpoint.

The focus of attention now shifts towards the pragmatist line of inquiry, and how its notions of valuation and imagination may help to integrate lessons from ANT for CSR with the advances made in Werhane's imagination centered systems approach. Waelbers and Dorstewitz (2014) suggest that Dewey's naturalism becomes an ethical theory by spelling out the 'method of intelligence' in the way we interact with our respective environments. Consequently, in using intelligence, we imaginatively project alternative ways of conducting and incorporating the results of thought experiments into the organization of our impending actions (Dorstewitz 2020). On this note, the form of intelligence that Dewey espouses is itself rooted in natural transactive processes. Transactions that lead to the formation of agency (organisms, organizations, or networked agents) also imply learning processes in problematic environments. Specific to intelligence in human systems of agency is "seeing the actual in the light of possibilities", i.e., using imagination in forward looking deliberation processes (Dewey 1922). This could be translated as a capacity of projecting courses of action and trends into the future, building scenarios, taking various perspectives, obtaining sympathetic standpoints respective others, transferring knowledge from one situation to another and even applying moral norms to specific contexts (cf. Dorstewitz 2020). Importantly in terms of Dewey, is that imagination is not a distinct faculty of the mind, but more of a form of functioning that individuals exhibit alone, and in organized form with others (Alexander 1990). Continuing with this line of inquiry, Dewey's pragmatist approach lend itself well to develop a model of intelligent deliberative agency (Figs. 3 and 4), that captures the situationally dependent transactive nature of agency in planning and policy processes (cf. Dorstewitz and Kuruvilla 2007; Kuruvilla and Dorstewitz 2010).

This model distinguishes three activity modes as intelligent responses to complex and problematic situations: "define" (defining the determinants of a problematic situation), "design" (determining hypothetical situation(s)), and "realize": implementing changes and learning. These sectional areas in this model are neither stipulated agents like organizations, stakeholder-groups, nor actants as in ANT, but should be seen as activity-modes that contribute to deliberate forms of cooperation through coordination of decision-making processes. The

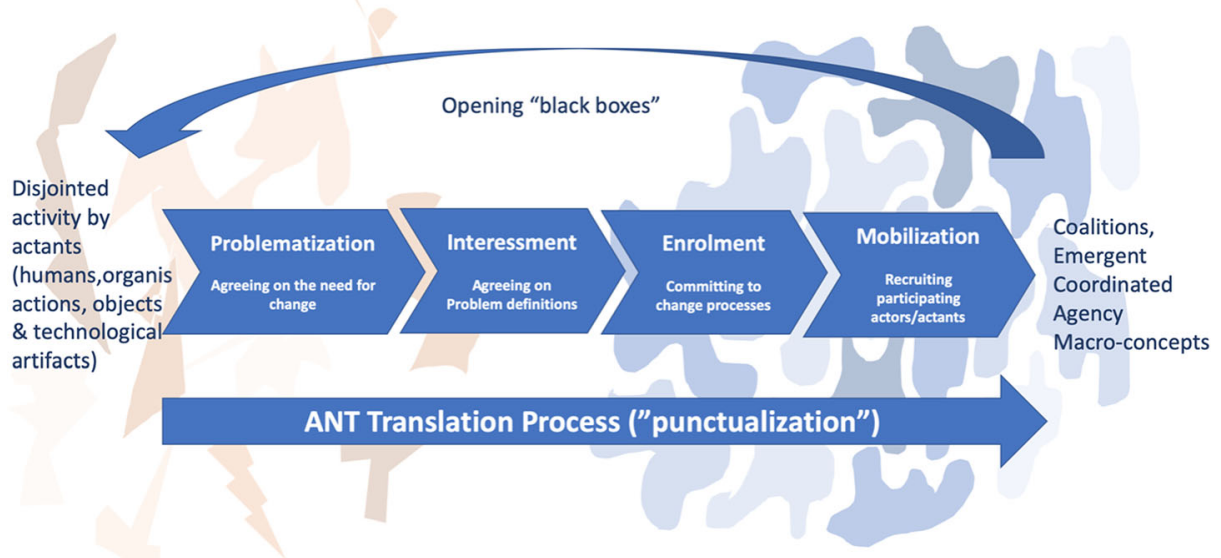

Fig. 3 ANT formation of agency coalitions 
POLICY ENVIRONMENTS

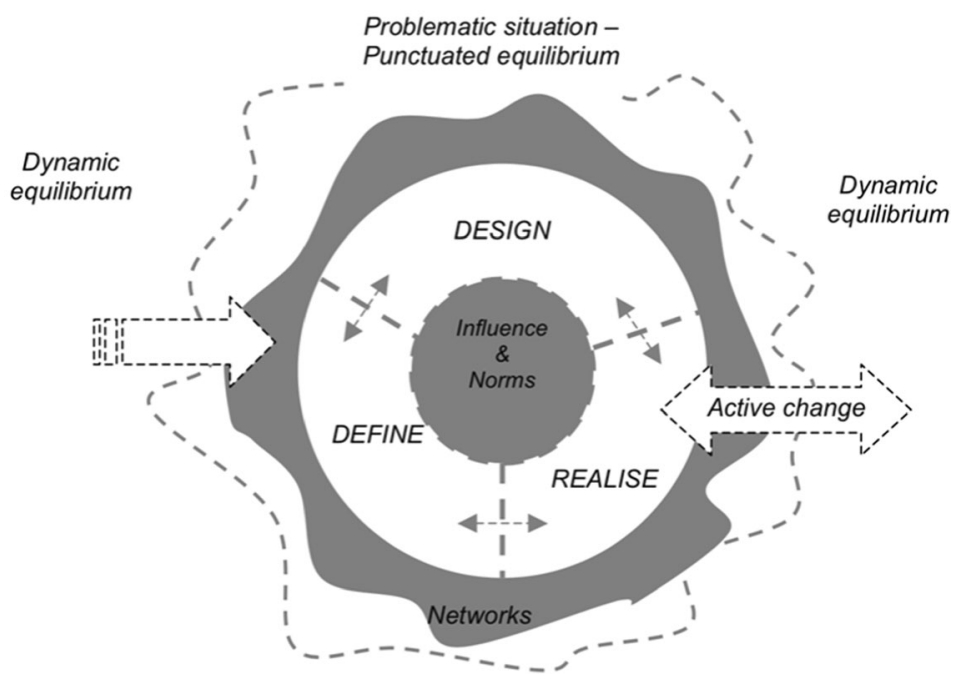

Fig. 4 Situational transactive model. (source: Kuruvilla and Dorstewitz 2010)

transactive nature of this model points at transformative agency as an emergent phenomenon whereby activities that can be identified as "define", "design" or "realise" take place in parallel on the initiative of interacting agents and coalitions, rather than following in a linear goaldirected pattern. This model establishes that situations tend to be unstructured, dysfunctional, uncoordinated and rather chaotic, however it demonstrates that, there is a much more innovative, dynamic approach towards permitting intelligence and effective learning processes to work toward resolving problematic situations, where more traditional agent-centred models of instrumental rationality tend to see only randomness, waste or power-struggles. However, although this model does attempt to manage complexity, it does not specifically address the issue of stakeholder coalitions and multi-sector collaborations in CSR. Consequently, Kuruvilla et al. (2018) developed the model further as presented in Fig. 5.

This model specifically addresses the formation of multi-sector stakeholder coalitions with respect to achieving Sustainable Developmental Goals and it addresses itself to the CSR debate. The model was designed for multi-sector network engagement with policy issues and it explicitly includes for-profit organizations. It identifies several additional activity modes specific to the deliberative formation of multi-actor and multi-sector agency coalitions in addressing complex CSR problems. These "relate" organizations in collaborative interactions, "capture success" by indicating the need to agree on success criteria, and "drive change" by mobilizing multi-sector agents to coalesce around dynamic initiatives. This model seems to dispense with an account of the dynamic transformation and resolution of indeterminate or problematic CSR situations over time. We believe that this dimension should be re-introduced. Furthermore, we believe that "imagination" as the functioning of projective intelligence should be established at the core of the model. The pragmatist concept of imagination captures the ideas of deliberating over possible futures and of including different standpoints and perspectives both rationally and empathetically. Imagination actually forms the crucial link in mediating between a systems perspective and ANT as discussed above. It refers to the very evaluative deliberative stance that is required in assembling complex stakeholder coalitions 


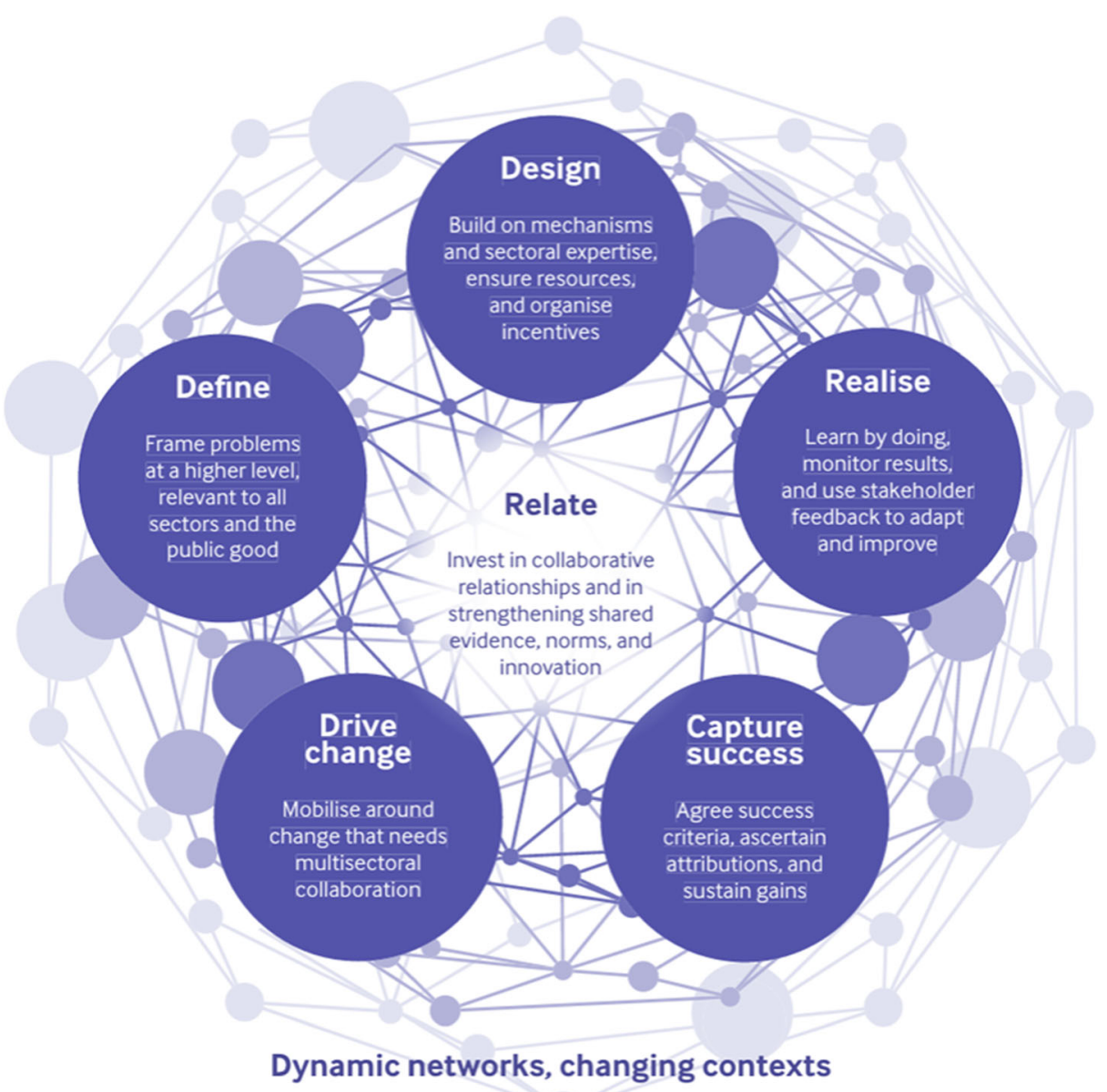

Fig. 5 Transformative change through multi-sector collaborations

through processes that ANT would characterize as "translation" and "punctualization" by means of testing and evaluating mental models Fig. 6.

In this contribution, a further constructive iteration of the Kuruvilla et al. (2018) model captures three ideas which are central to the discussion on managing the complexities of CSR. Notably, this particular model shows:

(1) The indeterminate situation: where dynamic transformation of situations over time are necessary to be better understood. Here, networks of actants (technology, humans, environmental objects, are transacting which are often marked by conflict, competition, translation, conflict of interest, power struggles, misunderstandings, miscommunications and chaotic and unstructured activities.

(2) The deliberate transactive formation of transformative agency situation: where we note the integration of system thinking, stakeholder mobilization, ANT analysis and Pragmatism; through mental modelling and imagination. 


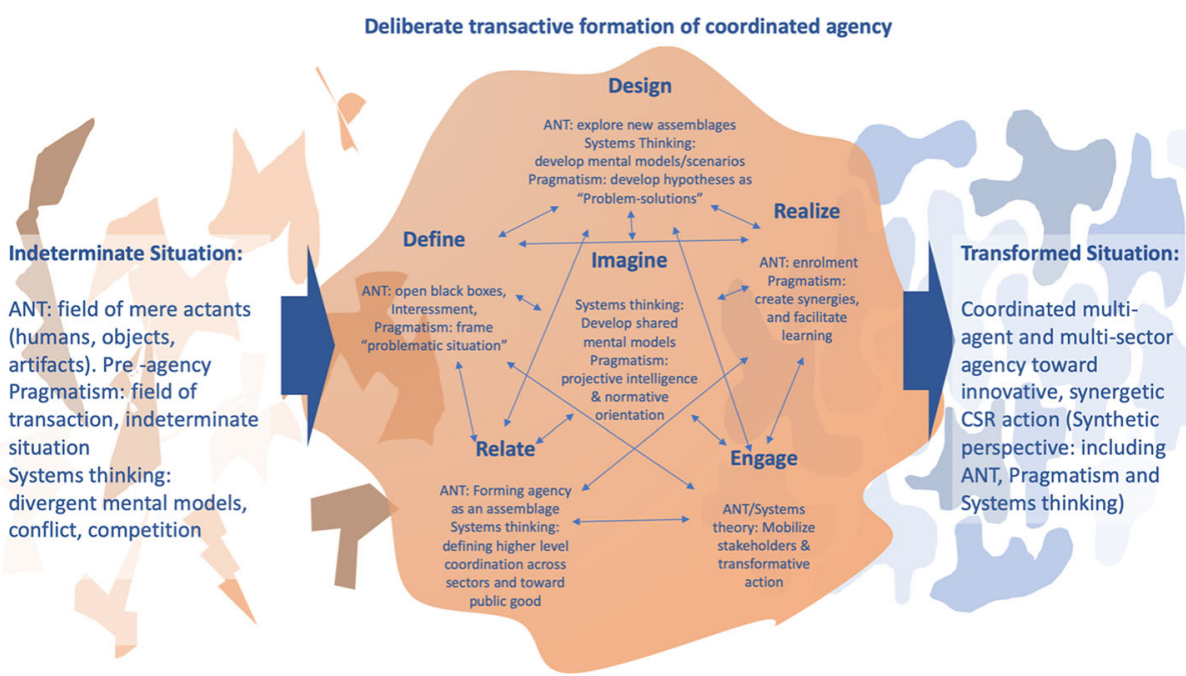

Fig. 6 Transformative CSR agency. (Source: Author Generated from Extant Theory)

(3) Transformed situation: where the shifting of perspectives between material, technological and human actants and higher order systems of agency to create a transformed situation of coordinated multi-agent and multi-sector agency towards achieving innovative, synergistic CSR actions.

This latest model envisages rapid transitions between activity modes in a deliberative process. It centers on the imaginative capacities to shift between sympathetic perspectives, to project and appreciate different futures and to develop normative orientations. The deliberation process as a whole is presented as a transition between indeterminate situations where active elements (actants) lack purposeful coordination, and a transformed situation that enables complex coordinated agency of multi-actor and multi-sector CSR engagement. This model is able to capture the material and transactive perspective of ANT, stakeholder theory, network theory, organizational learning and imagination, by dealing with activity-modes that include all actants (human and non-human) within a dynamic situation. In concluding, this model demonstrates that directed and coordinated agency should result as a product of these transitions.

\section{Conclusion}

Up to this point the purpose of this paper was to lay a foundation for an adequate agency theoretic approach to tackling CSR problems from an organizational point of view - with an integration of relevant models from extant theory. In comparing a prominent systems-thinking approach to CSR with ANT, it became clear that both approaches have valuable insights to offer: framing mental models in terms of interactive systems of stakeholder agents and opening new perspectives for collaborations and coalitions to tackle CSR problems. ANT allows the uncovering of dynamics and possibilities that are often hidden by the use of aggregated systems concepts, but it does offer a key towards transforming agency processes on the level of human and non-human transactions. This approach promised greater fundamental transformations, if it could be made useful in addressing CSR related problems in an imaginative, deliberative and evaluative way. A model of intelligent 
planning based on the pragmatist notions of imagination and situational transactive formation of agency was introduced as a step forward. This line of thinking may offer the key to thinking big and small at the same time, by allowing an understanding of agency formation, as depending on material, technological, human and environmental micro processes - and at the same time - taking a truly deliberative and imaginative stance towards searching for new and responsible ways of tackling complex CSR problem-situations of the past. This model should be used as a testing instrument for empirically based CSR studies in the examination, analysis of organizations from across industry sectors. E.g. it may help reframing the formation of public private partnerships to tackle the supply of covid 19 vaccine to people in developing countries by imaginatively reassembling multiple agencies into coalitions. This requires opening black boxes of existing organizations and vested interests (such as patent holders) to reframe possibilities for value creation in view of complex system dynamics. Also, the recent inclusion of two activists from the "engine 1" hedge fund on the board of directors of Exxon Mobile indicates the possibility of rethinking the agency framework of an oil and gas juggernaut in view changing perceptions of a global threat, both amongst investors and wider stakeholder groups. Finally, transformations on the energy sector away from centralized fossil fuel powered utilities toward decentralized renewable forms of energy production, storage and trade ask for rethinking a sector by simultaneously employing a systems' point of view while tracing the assemblage of micro-grid technologies.

\section{References}

Alexander, Thomas. 1990. Pragmatic imagination. Transactions of the Charles S. Peirce Society 26 (3): 326-348.

Alexander, Thomas. 1993. John Dewey and the moral imagination: Beyond Putnam and Rorty toward a postmodern ethics. Transactions of the Charles S. Peirce Society 19 (3): 369-400.

Aupperle, K.E., A.B. Carroll, and J.D. Hatfield. 1985. An empirical investigation of the relationship between corporate social responsibility and profitability. Academy of Management Journal 28: 446-463.

Barnard, C.I. 1938. The functions of the executive. Cambridge: Harvard University Press.

Bowen, H.R. 1953. Social responsibilities of the businessman. New York: Harper \& Row.

Callon, Michael. 1981. Struggels and negotiations to define what is problematic and what is not: the socio-logic of translation. In: The Social process of scientific investigations, eds. K. Knorr-Cetina, Roger G. Krohn, and Richard Whitley, xxvii, 328 p., vol. 4. Dordrecht; Boston Hingham: D. Reidel Pub. Co. ; sold and distributed in the U.S.A. and Canada by Kluwer Boston.

Callon, Michael. 1986. Some elements of a sociology of translation: The domestication of scallops and the fishermen of St. Brieuc Bay. In Power, action, and belief: A new sociology of knowledge? ed. John Law. London: Routledge \& Kegan Paul.

Carroll, A.B. 1991. The Pyramid of Corporate Social Responsibility: Toward the Moral Management of Organizational Stakeholders. Business Horizons 34: 39-48.

Carroll, A.B. 1994. Social issues in management research: Experts: Views, analysis and commentary. Business and Society 33: 5-29.

Carroll, A.B. 1999. Corporate social responsibility: Evolution of a definitional construct. Business and Society 38 (3): 268-295.

Checkland, Peter. 1981. Systems thinking, systems practice. Chichester: John Wiley.

Churchman, C.West. 1971. The Design of Inquiring Systems: Basic concepts of systems and organization. New York: Basic Books.

Clark, J.M. 1939. Social control of business. New York: McGraw-Hill.

Committee for Economic Development (CED). 1971. Social responsibilities of business corporations. New York: CED.

Davis, K. 1960. Can business afford to ignore social responsibilities? California Management Review 2: 70-76.

Davis, K. 1973. The case for and against business assumption of social responsibilities. Academy of Management Journal 16: 312-322. 
Dewey, John. 1922. Human Nature and Conduct. An introduction to social psychology. Vol. 7, 336. London: George Allen \& Unwin Rahway printed.

Dewey, John. 1934. Art as experience. New York: Minton.

Dorstewitz, Philipp. 2020. Provinces of imaginative intelligence: A taxonomy. Transactions of the Charles $S$. Peirce Society 56 (4): 600.

Dorstewitz, Philipp, and Shyama Kuruvilla. 2007. Rationality as situated inquiry: A pragmatist perspective on Policy \& Planning Processes. Management and Philosophy 6 (1): 91-117.

Eberstadt, N. N. 1973. "What history tells us about corporate responsibilities?" Business and Society Review/ Innovation, autumn: pp.76-81.

Eels, R. 1956. Corporate giving in a free society. New York: Harper.

Egels-Zandén, Niklas, and Evelina Wahlqvist. 2007. Post-partnership strategies for defining corporate responsibility: The business social compliance initiative. Springer Nature.

Eilbert, H., and R.I. Parket. 1973. The current status of corporate social responsibility. Business Horizons 16: 5-14.

Epstein, E.M. 1987. The corporate social policy process: Beyond business ethics, corporate social responsibility and corporate social responsiveness. California Management Review 29: 99-114.

Fischer, John Martin. 1999. Recent work on moral responsibility. Ethics 110 (1): 93-139.

Frederick, W.C. 1978. "From CSR1 to CSR2: The maturing of business and society thought". Graduate school of business: University of Pittsburgh. Working paper no. 279.

Freeman, E.R. 1984. Strategic management: A stakeholder approach. Boston: Pitman.

Freeman, E.R. 2004. The stakeholder approach revisited. Zeitschrift Für Wirtschafts- Und Unternehmensethik 5 (3): 228-241. https://doi.org/10.5771/1439-880X-2004-3-228.

Gond, Jean-Pascal, and Marion Ligonie. 2017. Building on actor-network analysis to study corporate social responsibility conceptual and methodological insights. In Cambridge handbook of research approaches to business ethics and corporate responsibility, ed. Patricia Hogue Werhane, R. Edward Freeman, and Sergiy Dmytriyev. Cambridge: CUP.

Griffin, J.J. 2000. Corporate Social Performance: Research Directions for the 21st Century. Business \& Society 39 (4): 479-491.

Harrison, J.S., and E.R. Freeman. 1999. Stakeholders, social responsibility, and performance: Empirical evidence and theoretical perspectives. Academy of Management Journal 42: 479-485.

Heald, M. 1957. Management's responsibility to society: The growth of an idea. The Business History Review 31: $375-384$.

Husted, B.W. 2000. A contingency theory of corporate social performance. Business and Society 39 (1): $24-48$.

Jensen, Tommy, and Johan Sandstrom. 2013. In Defence of stakeholder pragmatism. Journal of Business Ethics 114 (2): 225-237.

Johnson, H.L. 1971. Business in contemporary society: Framework and issues. Belmont: Wadsworth Publishing Co., Inc.

Jones, T.M. 1980. Corporate social responsibility revisited, redefined. California Management Review 22: 59-67.

Jones, R., and A.J. Murrell. 2001. Signaling positive corporate social performance: An event study of familyfriendly firms. Business and Society 40 (1): 59-78.

Keim, Gerald D. 1978. Corporate social responsibility: An assessment of the enlightened self-interest model. Academy of Management Review 3: 32-39.

Kotler, P., and N. Lee. 2005. Corporate social responsibility: Doing the Most good for your company and your cause. Hoboken: John Wiley \& Sons.

Kreps, T.J., and K.R. Murphy. 1940. Measurement of the social performance of business. US Government Print: Washington.

Kuruvilla, Shyama, and Philipp Dorstewitz. 2010. There is no "point" in decision-making: A model of transactive rationality for public policy and administration. Policy Sciences 43 (3): 263-287.

Kuruvilla, S., R. Hinton, T. Boerma, R. Bunney, N. Casamitjana, R. Cortez, P. Fracassi et al. 2018. Business not as usual: How multisectoral collaboration can promote transformative change for health and sustainable development. BMJ (Online) 363.

Latour, Bruno. 1991. Technology is sociology made durable. In A sociology of monsters : Essays on power, technology, and domination, ed. John Law. London: Routledge.

Latour, Bruno. 1994. On technical mediation: Philosophy, sociology, genealogy. Common knowledge 94 (4): $29-64$.

Latour, Bruno. 2005. Reassembling the social: An introduction to actor-network-theory. Oxford: Oxford University Press.

Latour, Bruno. 2008. Reassembling the social : An introduction to actor-network-theory. Oxford: Oxford University Press.

Law, John. 1986. Power, action, and belief : A new sociology of knowledge? Boston: Routledge \& Kegan Paul. Law, John. 1991. A sociology of monsters : Essays on power, technology, and domination. New York: Routledge. 
Law, J. (1992). Notes on the theory of the actor-network: ordering, strategy, and heterogeneity. Systems Practice 5 (4): 379-393.

Law, John. 2008. On sociology and STS. The Sociological Review 56 (4): 623-649.

Law, John, and John Hassard. 1999. Actor network theory and after. Sociological Review monographs. Oxford: Blackwell.

McGuire, J.W. 1963. Business \& Society. New York: McGraw-Hill.

Muirhead, S.A. 1999. Corporate contributions: The view from 50 years. New York: The Conference Board.

Murphy, P.E. 1978. "An evolution: Corporate social responsiveness”. University of Michigan Business Review 6 (30): 19-25.

Parsons, Talcott. 1977. Social systems and the evolution of action theory. New York: Free Press.

Samuelson, P.A. 1971. "Love that corporation". Mountain Bell Magazine, spring 1971.

Sandberg, J. 2008. Understanding the separation thesis. Business Ethics Quarterly 18 (2): 213-232. https://doi. org/10.5840/beq200818216.

Sassen, Saskia. 2013. Before method: Analytic tactics to decipher the global-An argument and its responses, part I. The Pluralist 8 (3): 79-82.

Sassen, Saskia. 2014. Expulsions : Brutality and complexity in the global economy. Cambridge: The Belknap Press of Harvard University Press.

Schwartz, M.S., and A.B. Carroll. 2003. Corporate social responsibility: A three-domain approach. Business Ethics Quarterly 13: 503-530.

Sethi, S.P. 1975. Dimensions of corporate social performance: An analytic framework. California Management Review 17: 58-64.

Steiner, G.A. 1971. Business and society. New York: Random House.

Ulrich, Werner. 1983. Critical heuristics of social planning. Bern: Paul Haupt.

Visser, W. 2014. The age of responsibility: CSR 2.0 and the new DNA of business. Journal of Law and Governance 5 (3): 7. https://doi.org/10.15209/jbsge.v5i3.185.

Waddock, S. 2004. Creating corporate accountability: Foundational principles to make corporate citizenship real. Journal of Business Ethics 50 (4): 313-327.

Waelbers, K., and P. Dorstewitz. 2014. Ethics in actor networks, or: What Latour could Learn from Darwin and Dewey. Science and Engineering Ethics 20 (1): 23-40.

Weaver, S.T., P.S. Ellen, and L. Mathiassen. 2015. Contextualist inquiry into organizational citizenship: Promoting recycling across heterogeneous organizational actors. Journal of Business Ethics 129 (2): 413-428.

Werhane, Patricia H. 1999. Moral imagination and management decision-making. New York: Oxford University Press.

Werhane, Patricia H. 2002. Moral imagination and systems thinking. Jbusiethi Journal of Business Ethics 38 (12): 33-42.

Werhane, Patricia H. 2008. Mental models, moral imagination and system thinking in the age of globalization. Journal of Business Ethics 78 (3): 463. https://doi.org/10.1007/s10551-006-9338-4.

Werhane, Patricia H. 2018. The Linguistic Turn, Social Construction and the Impartial Spectator: why Do these Ideas Matter to Managerial Thinking? Philosophy of Management (17): 265-278. https://doi.org/10.1007/ s40926-018-0086-1

Werhane, Patricia, Laura Hartman, Dennis Moberg, Elaine Englehardt, Michael Pritchard, and Bidhan Parmar. 2011. Social constructivism, mental models, and problems of obedience. Journal of Business Ethics 100 (1): 103-118. https://doi.org/10.1007/s10551-011-0767-3.

Wiener, Norbert. 2013 [1961]. Cybernetics. Martino Fine Books. Mansfield Centre, CT.

Publisher's Note Springer Nature remains neutral with regard to jurisdictional claims in published maps and institutional affiliations.

Dr. Philipp Dorstewitz is associate Prof of Philosophy at the American University of Ras Al Khaimah. He obtained his $\mathrm{PhD}$ in Philosophy from the London School of Economics in 2008. He studied Business Administration and Philosophy in Germany and in the UK. Before serving for five years as a lecturer in Philosophy at Maastricht University (Netherlands), he held teaching appointments at the LSE and the University College Dublin. His academic work gravitates around conceptions of intelligence and rationality. He studies deliberation processes in complex and ill-defined problem situations, e.g. in urban planning, policy and business management, whereby he draws upon methods from classical American Pragmatism, STS and Actor Network Theory. His work aims at showing how intelligent rational deliberation should not be reduced to efficient goaloriented optimisation: it should better be understood as a process of creative inquiry, involving imagination, research and learning. 
David Lal (recently retired) was formerly Professor of Business at The Higher Colleges of Technology (Sharjah, UAE), The American University of Ras Al Khaimah (UAE), and at the United Arab Emirates University (Al Ain, UAE). In addition, he was Professor and Dean at the Kazakh-British Technical University (Almaty, Kazakhstan) from 2007 - 2010, where his Chair was sponsored by HSBC Bank (Kazakhstan). David worked at the Robert Gordon University (Scotland) (1995-2008) and he is currently Visiting Professor of Strategy and International Business - at a number of European, Middle Eastern and Central Asian Universities. He graduated with MBA and $\mathrm{PhD}$ degrees from the University of Strathclyde (Scotland), where prior to these studies, David spent almost 14 years in the electronics industry with several multinational organisations prior to entering academia. Currently, he is heavily involved in consultancy and research within the governmental, finance and energy sectors and delivers courses to employees and students from many companies and countries. His primary research focuses on corporate-level strategic decision-making, organisational behaviour, environmental management strategy and international business.

\section{Affiliations}

\section{Philipp Dorstewitz ${ }^{1} \cdot$ David Lal $^{1}$}

\section{David Lal}

lal.david@ymail.com

1 American University of Ras Al Khaimah (AURAK), Ras Al Khaimah, United Arab Emirates 